\title{
Iranian Living Related Donors: Motivation for Kidney Donation
}

\author{
Ziba Borzabadi Farahani*, Maryam Esmaeili, Mahvash Salsali and Nahid Dehghan Nayeri
}

School of Nursing and Midwifery, Tehran University of Medical Sciences, Tehran, Iran

\begin{abstract}
Aim: This study sought to explore factors affecting Iranian living related donors' motivation for kidney donation.

Background: Living related donor kidney transplant is an ideal treatment among other options for chronic renal failure due to the greater compatibility of donor and recipient's human leukocyte antigen. Accordingly, identifying factors affecting living related donors' motivation for kidney donation is essential for transplant teams, including nurses, and can help them adopt strategies for encouraging family members to donate.

Methods: This was a descriptive qualitative study to which fourteen family donors (six females and eight males) were recruited purposively from transplantation centers of all teaching hospitals affiliated to Tehran University of Medical Sciences, Tehran, Iran. The study data were collected through in-depth semi-structured interviews and were analyzed by using the conventional content analysis approach.

Findings: Factors affecting Iranian living related donors' motivation for kidney donation fell into three main categories including feelings of love and responsibility, spiritual motives, and knowledge of greater success rate of living related donor transplant. The first category consisted of the two sub-categories of close and constant companionship and inability to tolerate recipient's discomfort.

Conclusion: The findings of the present study indicate that both personal factors (such as feeling of responsibility and spiritual motives) and organizational factors (such as informing family members about the importance and the benefits of family donation) are among the main motives for kidney donation by living related donors. Employing strategies for promoting these factors could facilitate the process of kidney donation by living related donors.
\end{abstract}

Keywords: Kidney donating; Living related donors; Motivation and content analysis; Qualitative research; Nursing

\section{Introduction}

The best treatment option for chronic renal failure is kidney transplant [1] whose success depends on donor-recipient human leukocyte antigens (HLA) compatibility [2]. The risk of transplant rejection is much lower once there is a blood relationship between donor and recipient. Therefore, family donor kidney transplant (FDKT) is among the most ideal treatment options which significantly improve post-transplant quality of life [3]. Studies have shown that compared with non-FDKT, FDKT is associated with reduced need for immunosuppressive therapy and greater survival rate [4,5]. Moreover, FDKT lasts longer than deceased-donor transplants [6]. Consequently, physicians emphasize greatly on performing FDKT than non-FDKT [7]. The results of a study in Iran indicated that post-FDKT quality of life and health status were significantly better than non-FDKT [8].

Donors have mixed and multidimensional motives for kidney donation. Nonetheless, previous studies provided insufficient information regarding family donors' motivation for donation, particularly kidney donation. Lennerling et al. reported wish to help, kindness, and personal benefit as the main motives for donation [9]. Other factors such as religious motives, sense of guilt, and sin expiation have been also rarely referred to as donation-related motives $[10,11]$. Despite the presence of strong motives for FDKT, there are also concerns over it. One of the main FDKT-related concerns is transplant rejection which can cause depression, grief, and a sense of loss for donors [12].

Physicians' first suggestion to patients and their family members is FDKT [7]. However, despite its greater success, the rate of FDKT in Iran is much lower than non-FDKT (MHME) [13]. Identifying family donors' motives for donation can help healthcare professionals, particularly nurses, adopt strategies for increasing FDKT rate. This study sought to explore factors affecting Iranian family donors' motivation for kidney donation.

\section{Methods}

This descriptive qualitative study aimed at exploring factors affecting Iranian family donors' motivation for kidney donation.

\section{Participants}

In total, fourteen family donors (six females and eight males) were recruited purposively from transplantation centers of all teaching hospitals affiliated to Tehran University of Medical Sciences, Tehran, Iran. The inclusion criteria were having an age of eighteen years or older and being physically and psychologically healthy. In order to recruit a maximum variation sample, we attempted to select the donors who were different in terms of demographic characteristics, types of family relationships with recipients (either blood or emotional), and posttransplant ages (Table 1).

\section{Data gathering}

The data were gathered via in-depth semi-structured personal interviews which were held either face-to-face or on the telephone. Data gathering lasted eight months from May to November 2015. The length of the interviews was 30-60 minutes. The main interview questions

*Corresponding author: Ziba Borzabadi Farahani, $\mathrm{PhD}$ in Nursing Education, School of Nursing and Midwifery, Tehran University of Medical Sciences, Tehran, Iran and Instructor, School of Nursing \& Midwifery, Shahid Beheshti University of Medical Sciences, Tehran, Iran, Tel: 98-21-66933600; E-mail: ziba farahani_2000@yahoo.com

Received: May 09, 2016; Accepted: June 15, 2016; Published: June 22, 2016

Citation: Farahani ZB, Esmaeili M, Salsali M, Nayeri ND (2016) Iranian Living Related Donors: Motivation for Kidney Donation. J Nephrol Ther 6: 253 doi:10.4172/2161-0959.1000253

Copyright: @ 2016 Farahani ZB, et al. This is an open-access article distributed under the terms of the Creative Commons Attribution License, which permits unrestricted use, distribution, and reproduction in any medium, provided the original author and source are credited. 


\begin{tabular}{|c|c|}
\hline \multicolumn{1}{|c|}{ Characteristics' N (\%) } \\
\hline Female & $6(43)$ \\
\hline Male Educational status \\
\hline Elementary \\
\hline Diploma \\
\hline Bachelor \\
\hline \multicolumn{1}{|c|}{ Age } \\
\hline Time after donation \\
\hline mean \pm SD \\
\hline <one year \\
\hline 1-5 year \\
\hline$>5$ year \\
\hline
\end{tabular}

Table 1: Donors demographic characteristics.

were what caused you to donate your kidney? How did you decide on donation? What do you mean by saying that this factor persuaded you? How did it persuade you? Besides these questions, we also used probing questions in order to clarify the participants' views. All interviews were conducted by the first author in Persian and then, they were translated into English. We recorded each interview by using a sound recorder and immediately transcribed it word by word.

\section{Ethical considerations}

This study was approved by the Ethics Committee and the Institutional Review Board of Tehran University of Medical Sciences, Tehran, Iran. The aim and the methods of the study were explained to the participants and they were ensured that they could withdraw from the study voluntarily and without experiencing any problems or disadvantages. Moreover, informed consent for participation in the study and recording the interviews was obtained from the participants. They were also assured that their data would remain confidential.

\section{Data analysis}

The conventional content analysis approach was used for data analysis. Content analysis is an analytic approach for analyzing scientific data. It reduces, organizes, and structuralizes data. It is a method for seeking the meanings hidden in data [14]. Accordingly, the transcribed interviews were read several times to get a general feeling about them. Each interview transcript was divided into condensed meaning units which were then abstracted and labeled with codes. Finally, the codes were categorized into subcategories and categories based on their similarities and differences.

\section{Trustworthiness}

Trustworthiness is among the key components of all phases of conducting qualitative studies and helps readers of research reports audit research-related events and researchers' effects and activities [15]. We employed the peer checking technique for enhancing the credibility of the findings. Accordingly, the data were coded and categorized independently by each of the authors and then, the categories generated by each author were compared with categories generated by the other authors. In case of any disagreement, we negotiated with each other until reaching a general agreement. In addition, the member-checking technique was used for ensuring credibility. A summary of the generated categories was given to some of the participants and they were asked to assess and confirm the compatibility of their experiences with our findings. Moreover, we documented all of our data collection and data analysis activities throughout the study for audit trailing.

\section{Findings}

Factors affecting Iranian family donors' motivation for kidney donation fell into three main categories including feelings of love and responsibility, spiritual motives, and greater success rate of FDKT. These categories are explained in detail in what follows.

\section{Feelings of love and responsibility}

One of the study participants' motives for donating kidney to their relative patients was that they tended to do something for their patients. In fact, they felt responsible to their patients' problems. They did not like to treat others' problems with indifference and attempted to do whatever they could for resolving the problems experienced by transplant recipient.

My father used to go to hospital for receiving dialysis and I accompanied him. During dialysis, I always asked myself, 'What can I do for my father?' (P. 1; recipient's daughter).

Our participants liked their sick family members and considered it as one of their own responsibilities to help them get rid of their problems. They provided their patients with unconditional and wholehearted help and support. They were continuously preoccupied with how to alleviate their sick family members' problems and discomfort.

I saw my brother suffering. I liked to help him very much. He was shouldering the biggest problem and I liked to help him (P. 7; recipient's sister).

The main category of feelings of love and responsibility consisted of two subcategories including close and constant companionship and inability to tolerate recipient's discomfort.

\section{Close and constant companionship}

Another factor affecting our participants' feeling of responsibility for kidney donation to their family members was close and constant companionship with recipients. Such a close and constant companionship had caused the participants to clearly understand recipients' conditions and hence, it had resulted in their decision on kidney donation in order to alleviate recipients' problems. The participating donors believed that closeness and companionship helped them better understand their sick family members' problems. Witnessing family members' pain and discomfort had been hard for the participants to tolerate and therefore, they felt responsible for alleviating family members' problems.

We have always been with each other, both before and after my spouse's retirement. We walk on street and go mountain climbing together (recipient's spouse).

According to the participants, close and constant companionship with patients help family members understand patients' problems well and increase their degree of commitment to do something for alleviating their patients' pain and discomfort. They also noted that close and constant companionship had made them experience deeper shared emotions with their patients and hence, required them to feel responsible for minimizing patients' problems.

\section{Inability to tolerate recipient's discomfort}

Our participants' another motive for FDKT was their inability to tolerate recipients' discomfort, love for their sick family members had made our participants feel responsible and decide on doing something for alleviating their patients' problems. Some of them noted that their patients' discomfort and suffering caused them great inconvenience and 
irritation because they were unable to tolerate witnessing their family members experience discomfort and suffering. They hoped that kidney donation alleviate their patients' problems. Some of them noted that they also experienced suffering due to their patients' physical problems.

Witnessing my sick family member's great discomfort caused me a sense of discomfort which was ten or one hundred times severer (P. 2; recipient's mother).

Some of the participants whose patients received hemodialysis referred to dialysis-related significant complications as the reasons behind their patients' physical and psychological problems. Accordingly, they considered kidney donation as a way for alleviating their patients' problems. They felt responsible for alleviating patients' problems.

I became irritated once my patient received dialysis and tolerated its related problems. I could not tolerate witnessing my patient's post-dialysis severe problems and discomfort (P. 8; recipient's brother).

\section{Spiritual motives for donation}

The third main category of the study was spiritual motives for donation. According to the participants, religious beliefs played a significant role in motivating them to donate. Some of them believed that donation was a way for expiating their past sins. They referred to faith in God, reliance on Him, and hope for a successful transplant as their main motives for donation. Some of them even accused themselves of causing their family members to develop renal failure and believed that donation was a way for alleviating their feelings of guilt. Such a practice was particularly common among the parents of sick children. They attributed their children's kidney disorders to their own consanguineous marriage and believed that donation was the least they could do for their children's recovery.

I don't know. I told myself that he is our child and our consanguineous marriage might have caused his disease. Otherwise, he may have never developed such a disease (P. 3; recipient's mother).

Some participants highly valued God's will, considered donation as a God-approved practice, and noted that God has helped them donate their kidneys. They noted that they donated their kidneys for gratifying God and believed that $\mathrm{He}$ sees and supervises them and hence, $\mathrm{He}$ would help them achieve the positive outcomes of donation. They reported that donation has brought them spiritual comfort. They not only referred to donation as an altruistic practice which gratifies God through alleviating patients' discomfort, but also believed that donation could facilitate their spiritual development.

\section{Greater success rate of FDKT}

The final main category of the study was the greater success of FDKT. In other words, obtaining information and realizing the greater benefits of FDKT had motivated the participants to opt for donation. Some of them reported that they had never thought about donation until obtaining information from their patients' physicians. However, after obtaining adequate information, they had made an irreversible decision about donation. Accordingly, a major motive for donation was the lower likelihood of FDKT rejection.

The doctor explained in such a way that we realized the greater longevity of family donor kidney transplantation. He said that family donor transplantation is less likely to be rejected (P. 8; recipient's brother).

On the other hand, some participants were concerned about their own post-donation health status. They had decided on donation after receiving information from physicians and understanding that donation would not be extremely harmful to them. In other words, they considered the positive outcomes of FDTK and low risk of postdonation health problems for themselves as the main motives for donation.

\section{Discussion}

In this study, family kidney donors were asked to explain the motives behind their decisions about kidney donation. Among their main motives were feelings of responsibility, lack of indifference, and tendency for doing something in order to alleviate their patients' problems. Tendency for doing something for a sick family member had been also cited in previous studies. For instance Sadeghi et al. reported strong emotional ties among family members and their commitment to each other's health as the main motives for helping a family member who develops problems [16]. Gill and Lowes also found that the main motive behind kidney donation to family members was to help them regain health [17]. We also found that the main motive of parents for donating kidney to their children was their love for their children as well as their tendency for alleviating their own feelings of guilt. Yeh et al. also reported that parents consider donation as an appropriate and natural method for saving their own children's lives [7]. However, the results of another study entitled 'Because you can't live on love' illustrated that financially recompensed family donors tended to donate kidney, referred to donation as the best decision in their immediate situations, and considered financial recompense as a way for covering the heavy costs of donation [18]. People have different motives for organ donation. Some of them donate their organs due to having internal motives such as tendency for alleviating pain and suffering and saving the lives of their relatives [10] while others' main motive for donation is gifting out of feeling responsible toward family members [19].

Our findings also revealed that another motive for kidney donation was close and constant companionship with patients and understanding their problems and conditions. A systematic review study also indicated that compared with the type of donor-recipient kinship (parents or siblings), intimacy has more powerful effect on donation-the closer the intimacy, the greater the donation tendency [12]. Moreover, the effect of constant companionship on donation is greater among parents, particularly mothers, due to their deeper attachment and intimacy with their sick children [7].

The study findings also indicated inability to tolerate recipient's discomfort as another motive for kidney donation. Some of the participants were unable to tolerate their patients' disease- and dialysisrelated problems and complications and hence decided to donate their kidneys in order to alleviate their patients' problems. In line with this finding Hildebrand and Chang also noted that witnessing their patients suffering disease- and dialysis-related problems is intolerable for family members and even friends [20,21]. Accordingly, one of the main motives behind kidney donation by them is patients' discomfort and suffering due to dialysis-induced changes in their lifestyle. According to Mazaris et al. family members consider transplant as a method for eliminating dialysis-related problems [22]. Sajjad et al. and Tong et al. also reported that adverse effects of dialysis on patients and their family members' lives as well as family members' inability to tolerate the problems of long-term dialysis are among the main motives for kidney donation by family members $[23,24]$.

The second main category of the study revealed that donor' religious beliefs were another motive for kidney donation. Some participants considered donation as expiation for their sins. The participating parents also noted that they decided on donation in order to alleviate 
their feelings of guilt toward their sick children [7]. Moreover, some of the participants believed that God has given them two kidneys and they felt compelled to donate one of them in order to save their beloved ones' lives. There are different viewpoints about religious motives for donation. Some people support and encourage donation and believe that it can be used for saving the lives of ill and needy humans while some others do not support and confirm donation [25]. For instance, the findings of a study made by Rodrigue et al. indicated that repentance of sins was among the rarest and the weakest motives for donation [26]. Mazaris et al. also noted that one of the weakest motives for donation was religious beliefs or feelings of guilt [22]. However, Khan et al. reported that religious beliefs have a significant role in deciding on donation and hence, getting pleasant feelings in life after a selfless generosity is one of the main motives for donation [19]. Brown et al. also found that faith and religious beliefs are among the motives for donation and can alleviate donation-related fears [27]. Consequently, presence of religious preachers in hospitals for spiritually supporting donors seems crucial [28].

The final main category of the study was the greater success rate of FDKT. The participants highlighted that their increased awareness of FDKT-related benefits and the little likelihood of serious complication for donors played an important role in deciding on donation. Although lack of knowledge has been recognized as a barrier to donation, only few studies have been conducted in this area [25]. Purnell et al. and Siegel et al. noted that lack of knowledge about the benefits of donation in different nations has created difficulties in organ donation so much so that it is among its major barriers which can dissuade potential donors from donation [29,30]. Alvaro et al. also found that the major barriers to donation were lack of knowledge about donation and its consequences as well as fear of donation due to lack of knowledge [31].

\section{Limitation of the Study}

Like other qualitative studies, generalizability of these results limited to other context.

\section{Conclusion}

The findings of the present study indicate that the main factors affecting family donors' motivation for kidney donation are feelings of love and responsibility, spiritual motives, and understanding the greater success rate of FDKT. Deciding on kidney donation is a complex process which is affected by both donors' beliefs and emotions and information provided by healthcare providers. Conducting further studies, particularly grounded theory studies, is recommended for exploring the process of decision making for kidney donation by family members. Moreover, studies into the experiences of patients who receive kidney from their family members would provide valuable information.

\section{Relevance to Clinical Practice}

The findings of this qualitative study can help the members of transplant teams, particularly nurses; understand factors affecting family donors' motivation for kidney donation. They can encourage family members for donation through providing them with adequate and comprehensive information regarding the positive outcomes of FDKT as well as asking religious preachers to help and support donors.

\section{What is known about this Topic?}

- The best treatment option for chronic renal failure is kidney transplant.

- Family donor kidney transplant is among the most ideal treatment options for chronic renal failure.

- Donors have mixed and multidimensional motives for kidney donation.

\section{What this Paper Adds}

- The main factors affecting family donors' motivation for kidney donation are feelings of love and responsibility, spiritual motives, and understanding the greater success rate of FDKT.

- $\quad$ Both personal factors (such as feeling of responsibility and spiritual motives) and organizational factors (such as informing family members about the importance and the benefits of family donation) are among the main motives for kidney donation by family members.

\section{Reference}

1. Kerkeni W, Rebai MH, Bouzouita A, Chakroun M, Slama RB, et al. (2015) The effect of body mass index at the time of donation on postoperative and remote consequences of nephrectomy in 189 living-related kidney donors. Arab J Urol 13: $221-224$

2. Tuladhar A, Shrestha S, Raut PP, Bhandari P, Shrestha P (2013) HLA antigen distribution in renal transplant recipients and donors. J Nepal Health Res Counc 11: 289-292.

3. Vemuru Reddy SK, Guleria S, Okechukwu O, Sagar R, Bhowmik D, et al. (2011) Live related donors in India: Their quality of life using world health organization quality of life brief questionnaire. Indian J Urol 27: 25-29.

4. Santori G, Barocci S, Fontana I, Bertocchi M, Taqliamacco A, et al. (2012) Kidney Transplantation from Living Donors Genetically Related or Unrelated to the Recipients: A Single-Center Analysis. Transplant Proc 44:1892-1896.

5. Nga HS, Garcia PD, Contti MM, Takase HM, de Carvalho MF, et al. (2015) Different induction therapies for kidney transplantation with living donor. J Bras Nefrol 37: 206-211.

6. Griva K, Ziegelmann JP, Thompson D, Jayasena D, Davenport A, et al. (2002) Quality of life and emotional responses in cadaver and living related renal transplant recipients. Nephrol Dial Transplant 17: 2204-2211.

7. Yeh EK, Hwu HG, Wu AC ( 2012) Donating a Kidney in Taiwan: A Study of 90 Relative Living Donors. J Exp Clin Med 4: 125-129.

8. Fallahzadeh MK, Jafari L, Roozbeh J, Singh N, Shokouh-Amiri H, et al. 2013) Comparison of Health Status and Quality of Life of Related Versus Paid Unrelated Living Kidney Donors. Am J Transplantation 13: 3210-3214.

9. Lennerling A, Forsberg A, Meyer K, Nyberg G (2004) Motives for becoming a living kidney donor. Nephrol Dial Transplant 19: 1600-1605.

10. Dew MA, Switzer GE, DiMartini AF, Myaskovsky L, Matoka MC (2005) Psychological Aspects of Living Organ Donation. Psychological Aspects of Living Organ Donation.

11. Kute VB, Shah PR, Vanikar AV, Gumber MR, Goplani KR, et al. (2012) Long term outcomes of renal transplants from spousal and living-related and othe living-unrelated donors: a single center experience. J Assoc Physicians India 60: 24-27.

12. Ummel D, Achille M, Mekkelholt J (2011) Donors and Recipients of Living Kidney Donation: A Qualitative Metasummary of Their Experiences. J Transplant 2011 626501

13. Ministry of Health and Medical Education (2008) Nursing Office Annual Report. Tehran: MHME (in Persian).

14. Streubert HJ, Carpenter DR (2007) Qualitative research in nursing: Advancing the Humanistic Imperative Lippincott. Williams \& Willkins, Philadelphia, USA.

15. Holloway I, Freshwater D (2007) Narrative Research in Nursing. WileyBlackwell, Malden, USA.

16. Sadegi T, Nayeri ND, Abbaszadeh A (2015) Waiting Time Facilitators from Viewpoint of Family Members of Patients Undergoing Surgery: A Qualitative Study. J Rafsanjan U Med Sci 14:199-210.

17. Gill P, Lowes L ( 2008) Gift exchange and organ donation : Donor and recipient experiences of live related kidney transplantation. Int J Nurs Stud 45: 1607-1617.

18. Shaw RM, Bell LJ (2014) 'Because you can't live on love': living kidney donors' 
Citation: Farahani ZB, Esmaeili M, Salsali M, Nayeri ND (2016) Iranian Living Related Donors: Motivation for Kidney Donation. J Nephrol Ther 6: 253. doi:10.4172/2161-0959.1000253

perspectives on compensation and payment for organ donation. Health Expect 18: 3201-3212.

19. Khan TT, Koshaji B, Kamal S, Said MT (2013) Motivation for living kidney donation in the developing world. Ann Transplant 18: 609-610

20. Hildebrand L ( 2012) Impression Management and Psychological Reactions of Living Kidney Donors. Dissertations, Marquette University.

21. Lin YH, Yang Y, Chen SY, Chang CC, Chiu, PF, et al. (2011) The depression status of patients with end stage renal disease in different renal replacement therapies. Int J Urol Nurs 15: 14-20.

22. Mazaris EM, Warrens AN, Smith G, Tekkis P, Papalois VE (2012) Live kidney donation: attitudes towards donor approach, motives and factors promoting donation. Nephrol Dial Transplant 27: 2517-2525.

23. Sajjad I, Baines LS, Salifu M, Jindal RM ( 2007) The Dynamics of RecipientDonor Relationships in Living Kidney Transplantation. Am J Kidney Dis 50: 834-854.

24. Tong A, Chapman JR, Wong G, Kanellis J, McCarthy G, et al. ( 2012) The Motivations and Experiences of Living Kidney Donors: A Thematic Synthesis. Am J Kidney Dis 60: 15-26.
25. Irving MJ, Tong A, Jan S, Cass A, Rose J, et al. ( 2012) Factors that influence the decision to be an organ donor: a systematic review of the qualitative literature. Nephrol Dial Transplant 27: 2526-2533.

26. Rodrigue JR, Widows MR, Guenther R, Newman RC, Kaplan B, et al. (2006) The expectancies of living kidney donors: do they differ as a function of relational status and gender? Nephrol Dial Transplant 21: 1682-1688.

27. Brown JB, Karley ML, Boudville N, Garg AX, Muirhead N (2008) The experience of living kidney donors. Health Soc Work 33: 93-100.

28. Cooper ML, Taylor GJ (1998) Organ and Tissue Donation: a Reference Guide for Clergy. Richmond, VA: SEOPF/UNOS.

29. Purnell TS, Hall YN, Boulware LE (2012) Understanding and overcoming barriers to living kidney donation among racial and ethnic minorities in the United States. Adv Chronic Kidney Dis 19: 244-251.

30. Siegel JT, O'Brien EK, Alvaro EM, Poulsen IA (2014) Barriers to living donation among low-resource Hispanics. Qual Health Res 24: 1360-1367.

31. Alvaro EM, Siegel JT, Nadra DT, William L, Alexander C (2008) Living kidney donation among Hispanics: A qualitative examination of barriers and Living kidney donation among Hispanics. Prog Transplant 18: 243-250. 